\title{
Inactivation of $\operatorname{ompX}$ Causes Increased Interactions of Type 1 Fimbriated Escherichia coli with Abiotic Surfaces
}

\author{
Karen Otto* and Malte Hermansson \\ Department of Cell and Molecular Biology, Microbiology, Göteborg University, Göteborg, Sweden
}

Received 21 July 2003/Accepted 3 October 2003

\begin{abstract}
During the initial steps of biofilm formation, bacteria have to adapt to a major change in their environment. The adhesion-induced phenotypic changes in a type 1 fimbriated Escherichia coli strain included reductions in the levels of several outer membrane proteins, one of which was identified as OmpX. Here, the phenotypes of mutant strains that differ at the $\mathrm{ompX}$ locus were studied with regard to adhesion, cell surface properties, and resistance to stress and antimicrobial compounds. The kinetics of adhesion were measured online by an extended quartz crystal microbalance technique for wild-type and mutant strains with a fimbriated or nonfimbriated background. Deletion of $\mathrm{ompX}$ led to significantly increased cell-surface contact in fimbriated strains but to decreased cell-surface contact in a nonfimbriated strain. Phenotypic characterization of the ompX mutant demonstrated that $о m p X$ interferes with proper regulation of cell surface structures that play a key role in mediating firm contact of the cell with a surface (i.e., type 1 fimbriae, flagellae, and exopolysaccharides). These phenotypic changes were accompanied by increased tolerance to several antibiotic compounds and sodium dodecyl sulfate. Based on these results, we propose that changes in the composition of outer membrane proteins during fimbria-mediated adhesion may be part of a coordinated adaptive response to the attached mode of growth.
\end{abstract}

Bacteria are able to attach to and colonize a variety of biotic and abiotic surfaces, which may lead to the formation of complex biofilms. The initial interactions of bacteria with abiotic surfaces can to a large extent be understood by physicochemical adhesion theories, such as the thermodynamic approach (1) or the classical or extended DLVO theory (named after its inventors, Derjaguin, Landau, Verwey, and Overbeek) (13, 41, 42). These theories explain adhesion as the result of a balance between attractive and repulsive forces, based on electrostatic interactions $(13,42)$ and additional hydration forces (41). However, bacteria express various cell surface structures, and the dynamic character of the adhesion process involves physiological and morphological changes of the attached bacteria which cannot be accounted for by these theories. For example, fimbriae, which are proteinaceous cell surface organelles extending from the cell, have been shown to influence the adhesion properties of bacterial cells (33). Not only do the fimbriae confer a different physicochemical character to the cell (30), but they also appear to be part of a surface-sensing mechanism $(27,31,44)$. Fimbria-mediated adhesion to host cells has been shown to induce selective expression of genes for virulence factors (44), and Escherichia coli may establish closer contact with host cells by shortening type 1 fimbriae upon attachment (27). We have previously shown that type 1 fimbria-mediated surface contact leads to distinct changes in the outer membrane protein composition, including reductions in the levels of many outer membrane proteins (31). These alterations imply that a change in the cell surface takes place immediately in response to attachment. However, whether the changes con-

* Corresponding author. Mailing address: Department of Cell and Molecular Biology, Microbiology, Göteborg University, Göteborg, Sweden. Phone: 46-31-7732580. Fax: 46-31-7732599. E-mail: Karen.Otto@gmm.gu.se. tribute to adhesion and biofilm formation remains to be determined.

OmpX is one of the outer membrane proteins that are present at significantly lower levels in attached cells than in planktonic cells (31). This protein was originally identified as one of several outer membrane proteins that increase $\sigma^{\mathrm{E}}$ activity when they are overexpressed (23). It belongs to a protein family which confers a distinct virulence phenotype and which includes OmpK17 of Klebsiella pneumoniae (7), OmpX of Enterobacter cloacae (12, 40), Ail of Yersinia enterocolitica (26), Pag and Rck of Salmonella enterica serovar Typhimurium (15), and Lom of lambda lysogens of E. coli (4). The Rck and Ail proteins are involved in serum resistance and/or adherence to and invasion of host cells; PagC is important for survival of macrophage attack; and OmpX of Enterobacter contributes to invasion of host cells. However, the role of OmpX in adhesion of $E$. coli remains unclear. The crystal structure of the protein reveals that there is a four-strand $\beta$-sheet protruding from the cell surface, which might influence binding to external proteins (43). However, deletion of ompX did not reduce adhesion to mammalian cells compared to the adhesion by the wild-type strain (24). Furthermore, ompX belongs to the mar regulon, which is expressed at a lower level in attached $E$. coli cells than in planktonic cells (21). This is consistent with our finding that there is a reduced level of this protein during adhesion (31).

To obtain a better understanding of changes that occur in the bacterial cell envelope upon surface contact, it is necessary to analyze the phenotypes of mutants with mutations in the outer membrane proteins whose levels are affected by adhesion. In this study, we investigated the influence of $\mathrm{ompX}$ expression on the initial adhesion of fimbriated and nonfimbriated $E$. coli cells to abiotic surfaces and on the interactions of attached cells with the surfaces. As measured online by an extended quartz crystal microbalance technique, cell-surface 
TABLE 1. E. coli strains and plasmids used in this study

\begin{tabular}{|c|c|c|}
\hline Strain or plasmid & Relevant characteristics & Reference \\
\hline \multicolumn{3}{|l|}{ Strains } \\
\hline PC31 & gal tonA phx argF rel & 17 \\
\hline MS7 & PC31 $\Delta$ fim::kan $\mathrm{Km}^{\mathrm{r}}$ & 39 \\
\hline MS7fim + & MS7pPKL4 Ap ${ }^{r} \mathrm{Cam}^{\mathrm{r}}$ & 37 \\
\hline MC1061 & $\Delta l a c X 74$ galK galU $\Delta($ araABC-leu $) 7679$ araD139 hsdR rpsL mcrB & 5 \\
\hline MC1061 ompX & MC1061ompX::cam $\operatorname{Cam}^{\mathrm{r}} \mathrm{Tc}^{\mathrm{r}}$ & 24 \\
\hline $\mathrm{KO} 3$ & PC31_ompX::cam Cam $^{\mathrm{r}}$ & This study \\
\hline KO6 & MS7DompX::cam $\mathrm{Cam}^{\mathrm{r}} \mathrm{Km}^{\mathrm{r}}$ & This study \\
\hline KO11 & PC31pBAD18 Ap ${ }^{\mathrm{r}}$ & This study \\
\hline KO18 & MS7pBAD18 $\mathrm{Ap}^{\mathrm{r}} \mathrm{Km}^{\mathrm{r}}$ & This study \\
\hline KO189 & PC31pKO23 Ap ${ }^{r}$ & This study \\
\hline KO190 & MS7pKO23 $\mathrm{Ap}^{\mathrm{r}} \mathrm{Km}^{\mathrm{r}}$ & This study \\
\hline \multicolumn{3}{|l|}{ Plasmids } \\
\hline pPKL4 & pBR322 carrying the fim operon, $\mathrm{Ap}^{\mathrm{r}} \mathrm{Cam}^{\mathrm{r}}$ & 37 \\
\hline pBAD18 & pBR322 origin with arabinose-inducible promoter, $\mathrm{Ap}^{\mathrm{r}}$ & 14 \\
\hline $\mathrm{pKO} 23$ & pBAD18 carrying $o m p X, \mathrm{Ap}^{\mathrm{r}}$ & This study \\
\hline
\end{tabular}

interactions were increased in the fimbriated $o m p X$ deletion strain. In an attempt to explain this effect, we determined the cell surface charges and cell surface hydrophobicities for the different strains, as well as the fimbriation, motility, and exopolysaccharide (EPS) production. Since the integrity of the outer membrane has an effect on stress resistance, we also studied the tolerance of the different strains to exposure to ethanol $(20 \%)$, heat stress $\left(42\right.$ and $\left.50^{\circ} \mathrm{C}\right)$, sodium dodecyl sulfate (SDS) $(0.4 \%)$, and various antibiotics.

\section{MATERIALS AND METHODS}

Bacterial strains and culture conditions. All strains used in this study are listed in Table 1. Strains were cultivated at $37^{\circ} \mathrm{C}$ in Luria-Bertani (LB) medium without shaking (22). Cells were harvested by centrifugation $(12,100 \times g$ for 10 min), washed in $0.2 \mathrm{M}$ Tris-buffered saline $(0.05 \mathrm{M}$ Tris- $\mathrm{HCl}$ buffer supplemented with $0.15 \mathrm{M} \mathrm{NaCl} ; \mathrm{pH} \mathrm{7.5)}$ ) and incubated in the same buffer for $24 \mathrm{~h}$. Prior to adhesion experiments, the cell suspensions were centrifuged $(12,100 \times$ $g$ for $10 \mathrm{~min})$ and resuspended in $0.2 \mathrm{M}$ Tris-buffered saline $(\mathrm{pH} \mathrm{7.5)}$ ) at the appropriate cell concentration (approximately $3 \times 10^{8}$ cells ml $^{-1}$ ). Growth of the different strains in LB medium was monitored at different temperatures $(22,37$, and $42^{\circ} \mathrm{C}$ ) and at different osmolarities (LB medium supplemented with 5, 15, or $20 \mathrm{~g}$ of $\mathrm{NaCl}$ liter $\left.^{-1}\right)$. In addition, we tested the ability of the strains to grow on MacConkey agar plates containing bile salts, as well as minimal medium with glucose, lactose, or glycerol as the sole carbon source.

Genetic techniques. The deletion of the $\operatorname{omp} X$ gene was transferred from strain MC1061 $\Delta o m p X$ by phage P1 vir transduction of the inserted chloramphenicol resistance marker into the appropriate $E$. coli strain (25). Deletion of ompX was verified by growth on LB medium plates containing chloramphenicol and by PCR (Biometra TRIO thermoblock).

To overexpress OmpX, we used a high-copy-number pBAD18 vector (14), in which ompX was expressed under control of the arabinose-inducible $\mathrm{P}_{\mathrm{BAD}}$ promoter. Expression was induced with $0.2 \%$ L-arabinose. Amplification of the ompX $X$ gene for overexpression was performed with oligonucleotide primers. The primer sequences were as follows: ompX-up, 5'CCCGAATTCTGAAAAAAAT TGCATGTCTTTCAGCA3'; and ompX-down, 5'GGGGGTACCGTGATTAGAAGCGGTAACCAA3'. The restriction sites for Eco RI and KpnI, incorporated into the oligonucleotides, are underlined. PCR with chromosomal DNA from $E$. coli strain PC31 as the template was performed for 30 cycles by using the Expand Long Template PCR system (Boehringer Mannheim) and the Taq and Pwo DNA polymerases. Cloning of the complete $\operatorname{omp} X$ gene was performed by using standard procedures (22). The presence of the desired plasmid was confirmed by restriction endonuclease digestion of plasmid DNA and PCR. The absence of PCR-introduced mutations was confirmed by sequencing. Overproduction of OmpX in strain KO189 upon induction was confirmed by SDSpolyacrylamide gel electrophoresis.

Adhesion assay with a quartz crystal microbalance (QCM) with dissipation monitoring (QCM-D). We used an extended QCM technique to measure changes in both frequency (i.e., mass changes on the surface) and energy dissi- pation (i.e., damping of the crystal's oscillation due to viscoelastic changes in the system caused by adhesion) (36). QCM experiments were carried out essentially as described previously (29). Briefly, 5-MHz crystals from Maxtek Inc. (Torrance, Calif.), coated with an evaporated gold film, were cleaned prior to the experiment as described by Höök et al. (16). Hydrophobic, methyl-terminated surfaces were obtained as described by Prime and Whitesides (35) by immersing clean crystals in a saturated solution of octadecylmercaptan (Aldrich Chemical Co. Ltd.) in hexane for at least $12 \mathrm{~h}$ at $22^{\circ} \mathrm{C}$. The temperature of the detection cell was maintained at $22^{\circ} \mathrm{C}$. The quartz crystal was mounted in a detection cell with electrodes connected to the driving unit via a relay to a signal generator. An alternating potential field across the crystal induced oscillation in the shear mode at the resonant frequency. Changes in the resonant frequency and the dissipation factor were measured with a time resolution of approximately $1 \mathrm{~s}$. Prior to QCM measurement, sterile $0.2 \mathrm{M}$ Tris-buffered saline ( $\mathrm{pH} 7.5$ ) was degassed by sonication in vacuum, and the temperature of buffer solutions and bacterial suspensions was stabilized at $22^{\circ} \mathrm{C}$. Bacterial suspensions were added to a final concentration of approximately $3 \times 10^{8}$ cells $\mathrm{ml}^{-1}$. To measure initial interactions of bacterial cells with the surface, the frequency and dissipation shifts caused by adhesion of bacteria to the crystal surface were measured continuously for 30 min in $0.2 \mathrm{M}$ Tris-buffered saline ( $\mathrm{pH} \mathrm{7.5)} \mathrm{(Fig.} \mathrm{1A).} \mathrm{To} \mathrm{measure} \mathrm{interactions} \mathrm{of}$ cells with the surface following attachment, cells were allowed to adhere to the surface for $60 \mathrm{~min}$. Subsequently, the measuring chamber was rinsed to avoid further attachment of bacteria, and subsequent frequency and dissipation shifts were measured for an additional $60 \mathrm{~min}$ (Fig. 1B).

Microscopy. The cell concentrations in the experiments and the numbers of attached cells on the surfaces were determined by acridine orange direct counting and epifluorescence microscopy as previously described (29).

Determination of cell surface properties. The overall cell surface charges and cell surface hydrophobicities were determined for the different strains after $24 \mathrm{~h}$ of incubation in $0.2 \mathrm{M}$ Tris-buffered saline ( $\mathrm{pH} 7.5$ ) by measuring zeta potential and microsphere adhesion to cells as described previously (30).

The capacity to express a D-mannose binding phenotype (i.e., type 1 fimbriae) was examined by yeast agglutination and Western analysis. The mannose-sensitive agglutination titer was assessed by mixing twofold dilutions of the different strains with yeast cells in $0.4 \mathrm{M}$ Tris-buffered saline as described previously (30). For Western analysis, the amounts of protein were adjusted by using the reciprocal of the optical density at $600 \mathrm{~nm}$ to determine the appropriate sample volume. This volume was harvested and resuspended in $20 \mu \mathrm{l}$ of SDS-polyacrylamide gel electrophoresis sample buffer (0.2 M Tris-buffered saline, $1 \%$ SDS, 80 $\mu \mathrm{M}$ EDTA, $26 \mathrm{mM}$ dithiothreitol; $\mathrm{pH}$ 8.0). Protein samples $(20 \mu \mathrm{l})$ were applied directly onto a nitrocellulose membrane by using a slot blot apparatus (Schleicher \& Schuell), and type 1 fimbriae were quantified by probing the membrane with polyclonal antibodies for FimA. Anti-rabbit immunoglobulin G conjugated to horseradish peroxidase was used as the secondary antibody.

The motility of the strains was analyzed on semisolid LB medium plates containing $0.3 \%$ agar. The plates were incubated at $37^{\circ} \mathrm{C}$, and the diameters of the swarming zones were measured at several times.

EPS production was quantified as described by Dall and Herndon (8), except that the samples were resuspended in $0.2 \mathrm{M}$ Tris-buffered saline $(\mathrm{pH} 7.5)$ instead of saline. 


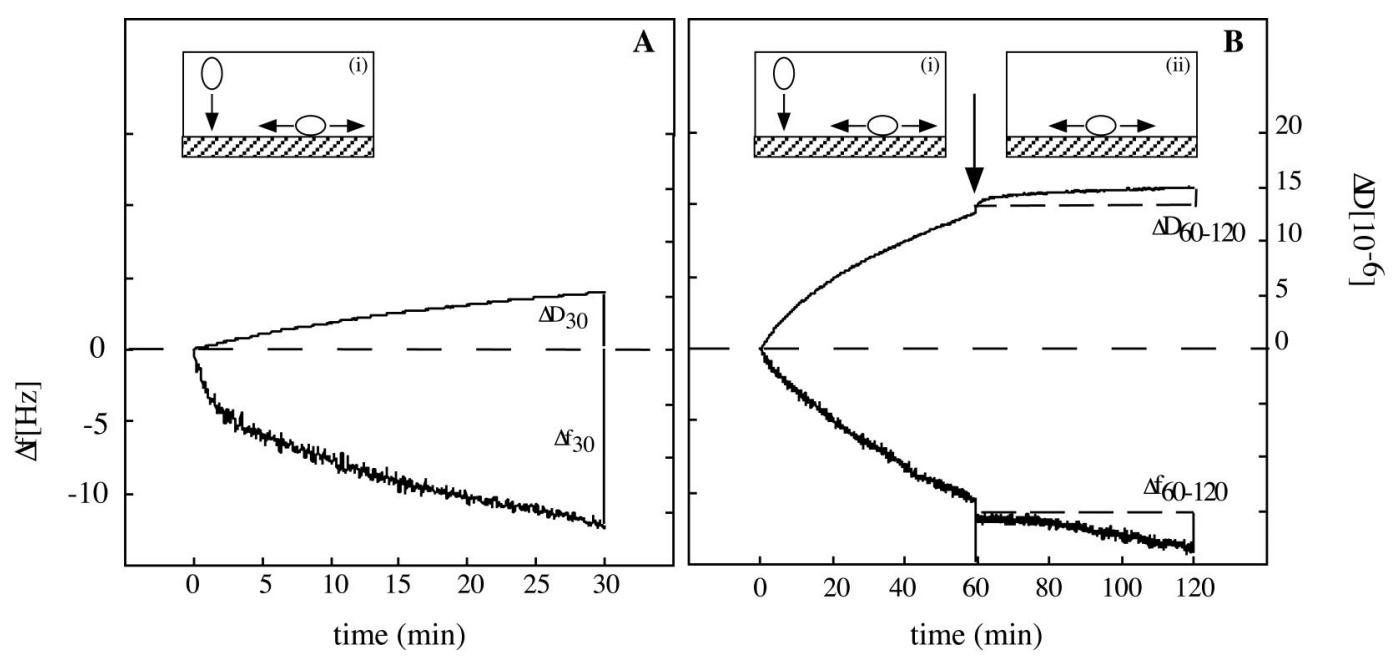

FIG. 1. Representative graphs showing the frequency shifts $(\Delta \mathrm{f})$ versus time (lower lines) and the dissipation shifts $(\Delta \mathrm{D})$ versus time (upper lines) measured by the QCM-D technique for E. coli strain KO3 for $30 \mathrm{~min}$ on a hydrophilic surface (A) and for 120 min on a hydrophobic surface (B). The values for frequency and dissipation shifts after $30 \min \left(\Delta \mathrm{f}_{30}\right.$ and $\left.\Delta \mathrm{D}_{30}\right)$ are indicated in panel A. The arrow in panel $\mathrm{B}$ indicates the time of a rinse with sterile Tris buffer that removed all planktonic cells. The values for frequency and dissipation shifts during $1 \mathrm{~h}$ after the rinse $\left(\Delta \mathrm{f}_{60-120}\right.$ and $\left.\Delta \mathrm{D}_{60-120}\right)$ are indicated in panel $\mathrm{B}$. The inserts show that the signals measured after 30 or 60 min were due to attachment of cells, as well as interactions of attached cells with the surface (i), and that the signals measured during the second hour of the adhesion experiment were only due to interactions of attached cells with the surface (ii).

Determination of resistance to stress or antibiotic compounds. Cells taken from suspensions after $24 \mathrm{~h}$ of incubation in $0.2 \mathrm{M}$ Tris-buffered saline $(\mathrm{pH} 7.5)$ were washed $(12,100 \times g$ for $10 \mathrm{~min})$ and resuspended in $0.2 \mathrm{M}$ Tris-buffered saline ( $\mathrm{pH} 7.5)$. To determine the resistance to different kinds of stress, these suspensions were diluted $1: 10$ in $0.2 \mathrm{M}$ Tris-buffered saline $(\mathrm{pH} 7.5)$ that had been preheated to 42 or $50^{\circ} \mathrm{C}$ or were supplemented with either 10 or $20 \%$ ethanol or $0.4 \%$ SDS. Aliquots $(100 \mu \mathrm{l})$ were taken after 5, 10, 20, 30, and $60 \mathrm{~min}$ of exposure, diluted serially, and spread on LB medium plates. After overnight incubation at $37^{\circ} \mathrm{C}$, viable counts were determined from the number of $\mathrm{CFU}$ and compared to the viable counts of untreated samples.

Resistance to antibiotic compounds (Difco) was tested by the disk diffusion assay on LB medium plates by using the following amounts: amikacin, $30 \mu \mathrm{g}$; cephalosporin, $30 \mu \mathrm{g}$; gentamicin, $10 \mu \mathrm{g}$; nalidixic acid, $30 \mu \mathrm{g}$; novobiocin, $30 \mu \mathrm{g}$; and compound sulfonamides, $300 \mu \mathrm{g}$. The plates were incubated at $37^{\circ} \mathrm{C}$ overnight, and the radius of each inhibition zone was measured.

\section{RESULTS}

Inactivation of $\mathrm{ompX}$ increases cell-surface interactions of fimbriated cells but not cell-surface interactions of nonfimbriated cells. To analyze the role of $o m p X$ in adhesion of $E$. coli to abiotic surfaces, we used an extended QCM-D technique. In addition to allowing us to determine the number of attached cells at the end of each experiment, this method allowed us to measure both negative frequency shifts and positive dissipation shifts as dynamic parameters of the adhesion process (Fig. 1). While the frequency shift per attached cell may be understood as a change in the contact area between the cell and the surface, the dissipation shift per attached cell may be interpreted as a viscoelastic change in the interaction between cells and the surface.

The numbers of attached cells, as determined by acridine orange direct counts after $30 \mathrm{~min}$ (Fig. 2) and $120 \mathrm{~min}$ (Fig. 3) of adhesion, did not differ significantly for the strains with altered expression of $\operatorname{omp} X$ (data not shown). However, the initial interactions between $E$. coli and abiotic surfaces, which were measured continuously for $30 \mathrm{~min}$, were clearly influenced by the expression of $\operatorname{ompX}$, as indicated by changes in both frequency and dissipation shifts per attached cell (Fig. 2). In this set of experiments (Fig. 1A), the measured frequency and dissipation shifts were caused both by cells attaching to the surface and by attached cells undergoing changes in contact with the surface. Subsequently, the number of attached cells was determined, and the final relative frequency and dissipation shifts after 30 min were calculated per attached cell.

Deletion of $o m p X$ affected cell-surface interactions of fimbriated and nonfimbriated cells in opposite ways. For fimbriated cells, the frequency shifts per attached cell after $30 \mathrm{~min}$ increased two- to threefold when $\operatorname{ompX}$ was absent on both hydrophilic and hydrophobic surfaces (Fig. 2A). The corresponding dissipation shifts per attached cell increased only slightly (1.3-fold) on hydrophilic surfaces, but they clearly increased (2.6-fold) on hydrophobic surfaces (Fig. 2C). Similar effects were also seen with a strain in which fimbriae were constitutively expressed from a multicopy plasmid (data not shown). In contrast, the frequency shifts per attached cell after 30 min for strain KO6, which lacked both ompX and the fim operon, were lower on hydrophilic (2-fold) and hydrophobic (2.5-fold) surfaces than values for the nonfimbriated parental strain (Fig. 2B). The corresponding dissipation shifts per attached cell were also lower on hydrophilic surfaces (2.5-fold) and hydrophobic surfaces (9.4-fold) (Fig. 2D). The adhesion parameters measured for the $\mathrm{omp} X$-deficient strains $\mathrm{KO} 3$ and KO6 were restored to the levels obtained for the corresponding $\mathrm{ompX} \mathrm{X}^{+}$strains by complementation with $\mathrm{ompX}$ on a highcopy-number plasmid (data not shown).

To investigate whether the absence of OmpX also influences later interactions of attached cells with the surface, we performed another set of experiments (Fig. 1B), in which cells were allowed to attach to a crystal surface for $60 \mathrm{~min}$. After this period of adhesion, we continued to obtain measurements, but the bacterial suspension was replaced by the same volume of buffer solution so that no additional cells could adhere to the 


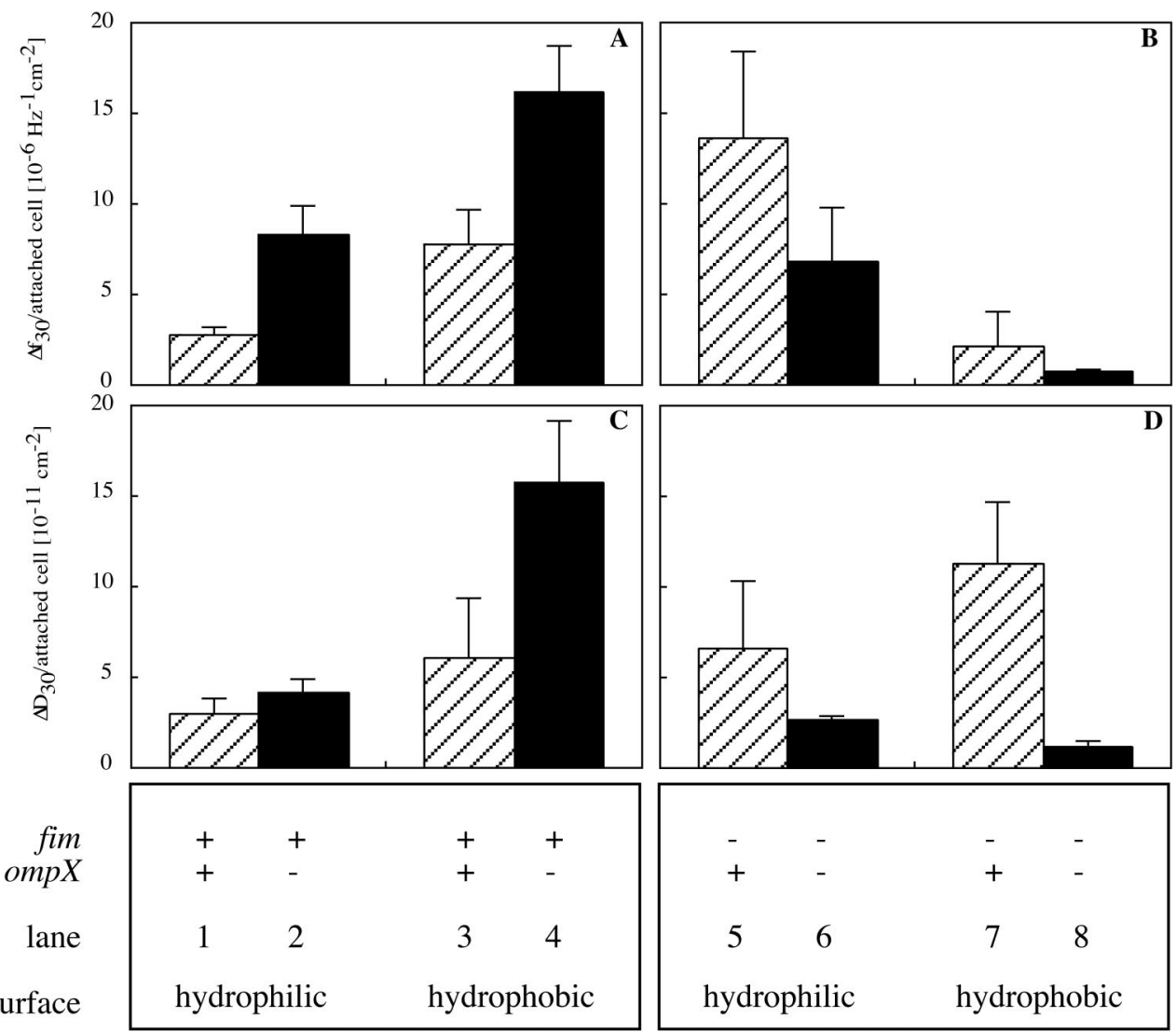

FIG. 2. Influence of OmpX on the initial adhesion of E. coli to hydrophilic and hydrophobic surfaces. (A and B) Relative mass increases on the surface per cell after $30 \mathrm{~min}\left(\Delta \mathrm{f}_{30} /\right.$ attached cell) for fimbriated strains $(A)$ and for nonfimbriated strains $(B)$. (C and D) Relative changes in the viscoelastic properties per cell after $30 \mathrm{~min}\left(\Delta \mathrm{D}_{30} /\right.$ attached cell) for fimbriated strains $(C)$ and for nonfimbriated strains (D). Lanes 1 and 3 show the results for wild-type strain PC31, lanes 2 and 4 show the results for $\mathrm{ompX}$ mutant KO3, lanes 5 and 7 show the results for nonfimbriated strain MS7, and lanes 6 and 8 show the results for nonfimbriated $o m p X$ mutant KO6. The data are means \pm standard deviations for two to five separate experiments.

surface. Changes in the frequency and dissipation shifts per cell were measured for one additional hour; thus, we monitored changes in cell-surface interactions arising from reorganization of cells already attached to the surface. At the end of these experiments, the number of attached cells was determined, and the relative frequency and dissipation shifts per attached cell during the last 60 min were calculated. Even after this prolonged period of adhesion, fimbriated ompX deletion mutants exhibited increased frequency and dissipation shifts, especially on hydrophilic surfaces (eightfold) (Fig. 3A). On hydrophobic surfaces, threefold increases in the frequency per cell were observed, which in contrast to early cell-surface interactions were not accompanied by significant increases in dissipation shifts (Fig. 3C). Prolonged adhesion of the ompX fim double mutant resulted in frequency and dissipation shifts that were indistinguishable from those of the parental strain (Fig. 3B and D). Constitutive expression of omp $X$ had no effect on the frequency and dissipation shifts per cell on hydrophilic or hydrophobic surfaces, independent of the fimbriated or nonfimbriated strain background (data not shown). Corresponding results were obtained for ompX-proficient and -deficient MC1061 strains with a different genetic background (data not shown).
Effect of ompX expression on physicochemical cell surface properties. Phenotypic changes caused by deletion or overexpression of $o m p X$ were studied with an emphasis on the effects on cell surface properties after starvation in $0.2 \mathrm{M}$ Tris-buffered saline ( $\mathrm{pH} 7.5$ ) for $24 \mathrm{~h}$ since adhesion studies have been performed under the same conditions. Deletion of $\operatorname{omp} X$ led to small but significant alterations in the cell surface hydrophobicity and cell surface charge (Table 2). Independent of the presence of fimbriae, cell surface hydrophobicity was increased in the ompX deletion strains. Zeta potentials, which represented the overall surface charge of the cells, were more negative when $o m p X$ was deleted, in both fimbriated and nonfimbriated strain backgrounds. Overexpression of $\mathrm{ompX}$ did not contribute to a significant change in the cell surface hydrophobicity and cell surface charge (data not shown).

Production of type 1 fimbriae is upregulated in the absence of ompX. One striking observation in the adhesion experiments was that inactivation of OmpX enhanced cell-surface interactions of fimbriated cells but not cell-surface interactions of nonfimbriated cells. This prompted us to study whether the production of fimbriae was affected by the expression of ompX. The different strains were examined for the presence of type 1 


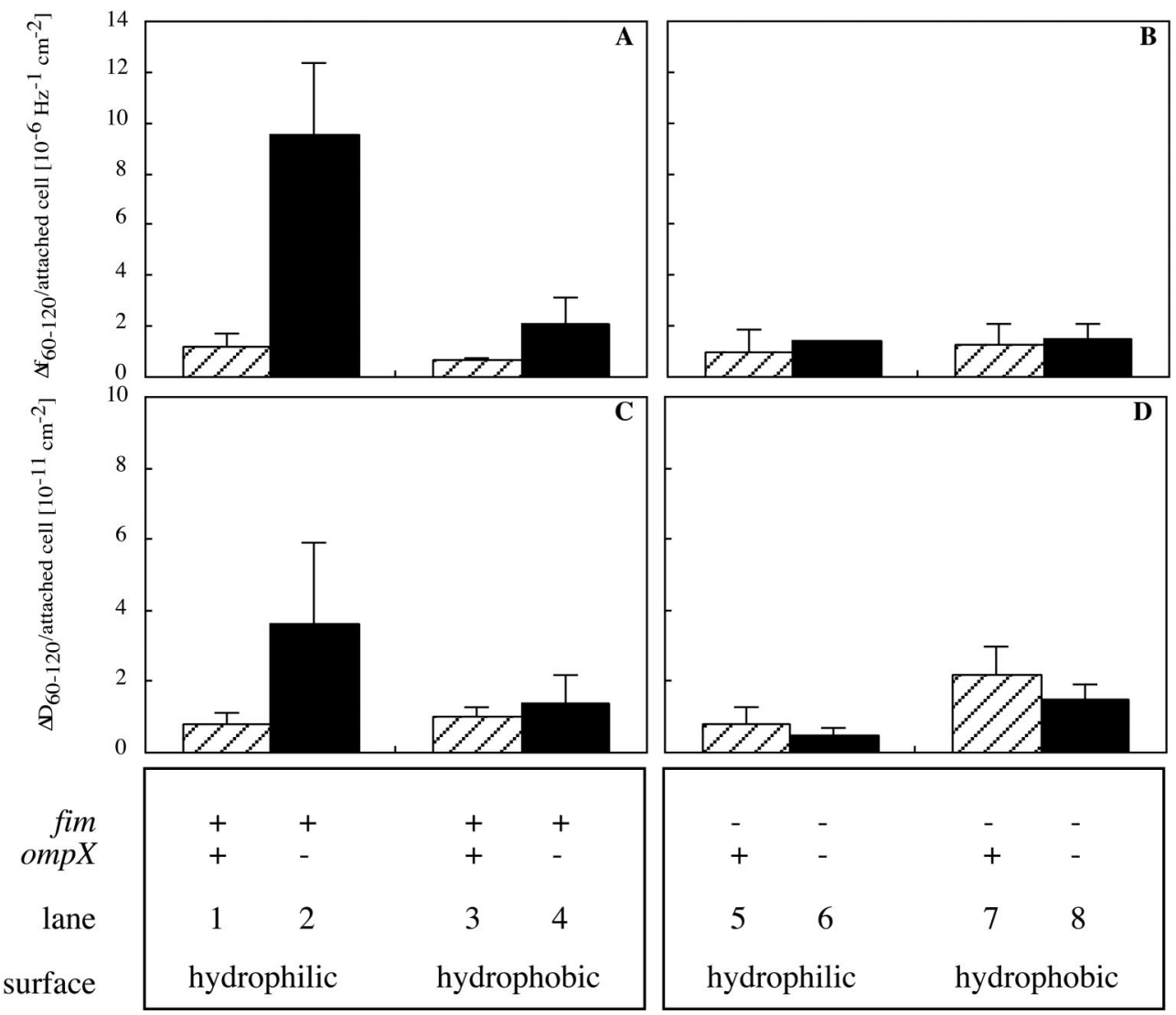

FIG. 3. Influence of OmpX on interactions of attached E. coli cells with hydrophilic and hydrophobic surfaces. (A and B) Relative mass increases on the surface per cell from 60 to $120 \mathrm{~min}\left(\Delta \mathrm{f}_{60-120} /\right.$ attached cell) for fimbriated strains (A) and for nonfimbriated strains (B). (C and D) Relative changes in the viscoelastic properties per cell from 60 to $120 \mathrm{~min}\left(\Delta \mathrm{D}_{60-120} /\right.$ attached cell) for fimbriated strains $(\mathrm{C})$ and for nonfimbriated strains (D). Lanes 1 and 3 show the results for wild-type strain PC31, lanes 2 and 4 show the results for ompX mutant KO3, lanes 5 and 7 show the results for nonfimbriated strain MS7, and lanes 6 and 8 show the results for nonfimbriated ompX mutant KO6. The data are means \pm standard deviations for two to five separate experiments.

fimbriae by using yeast agglutination and reactivity with specific antiserum.

The mannose-sensitive agglutination of yeast cells (i.e., the presence of type 1 fimbriae) was greater in the $\operatorname{omp} X$-deficient strain KO3 than in the wild type (Fig. 4A). When ompX was overexpressed, the agglutination titer was slightly reduced. As expected, a mutant lacking the fim operon did not agglutinate yeast cells, which confirms that the agglutination phenotype is caused by the presence of type 1 fimbriae and not by the presence of other cell surface appendages.

TABLE 2. Overall cell surface properties of E. coli strains

\begin{tabular}{|c|c|c|c|}
\hline Strain & Relevant genotype & $\begin{array}{l}\text { Cell surface } \\
\text { hydrophobicity (mean } \\
\pm \mathrm{SD})(\%)^{a}\end{array}$ & $\begin{array}{l}\text { Zeta potential } \\
(\mathrm{mV})\end{array}$ \\
\hline PC31 & Wild type & $3.5 \pm 0.8^{b}$ & $-30.0 \pm 5.3^{b}$ \\
\hline KO3 & $\Delta o m p X:: c a m$ & $5.6 \pm 0.4$ & $-38.6 \pm 5.3$ \\
\hline MS7 & fim::kan & $1.2 \pm 0.5^{b}$ & $-33.3 \pm 3.6^{b}$ \\
\hline KO6 & $\Delta o m p X:: c a m$ fim::kan & $3.1 \pm 0.2$ & $-37.0 \pm 2.8$ \\
\hline
\end{tabular}

${ }^{a}$ The values are the percentages of cells in a population with three or more attached hydrophobic microspheres. Adsorption of a high number of microspheres per cell is related to a high level of cell surface hydrophobicity, as determined by microsphere adhesion to cells.

${ }^{b}$ Data from reference 30 .
Western analysis of the different strains confirmed that there was increased production of FimA, the major structural subunit of type 1 fimbriae, in the ompX-deficient strain (Fig. 4B). Overproduction of OmpX slightly affected the level of FimA production.

Taken together, these results show that the production of type 1 fimbriae is upregulated in an ompX-deficient strain.

Motility of fimbriated $o m p X$ mutants is impaired. It has been shown previously that adhesion of hyperfimbriated cells causes low-level frequency and dissipation shifts compared to the shifts of nonfimbriated cells, suggesting that fimbriated cells make less contact with the surface (29). However, adhesion of the $\operatorname{omp} X$ mutant caused greater frequency and dissipation shifts than adhesion of the less fimbriated wild-type strain caused. Thus, the dynamic character of the cell-surface interactions of the ompX mutant cannot be explained solely by upregulation of type 1 fimbriae but must be due to additional changes in the cell surface.

Flagella are another dominant cell surface structure often implicated in adhesion of $E$. coli. To assess the potential role of motility in the altered cell-surface interactions measured by the QCM technique, we compared the swarming behaviors of the different strains on soft agar plates. Motility was decreased in 


\begin{tabular}{|c|c|c|c|c|c|c|}
\hline $\begin{array}{l}\text { agglutination } \\
\text { titer }\end{array}$ & A ND & $1: 256$ & $1: 16$ & $1: 64$ & $1: 16$ & $1: 8$ \\
\hline FimA & B & & $x=x$ & & $=$ & $x^{2}+x^{2} x^{2}$ \\
\hline $\begin{array}{l}\text { ompX } \\
\text { fim } \\
\text { plasmid }\end{array}$ & $\begin{array}{l}+ \\
- \\
-\end{array}$ & $\begin{array}{c}+ \\
+ \\
\text { pKL404 }\end{array}$ & $\begin{array}{l}+ \\
+ \\
-\end{array}$ & $\begin{array}{l}- \\
+ \\
-\end{array}$ & $\begin{array}{c}+ \\
+ \\
\mathrm{pKO} 23\end{array}$ & $\begin{array}{c}+ \\
+ \\
\text { pKO23 } \\
\text { induced }\end{array}$ \\
\hline strain & MS7 & MS7+ & PC31 & $\mathrm{KO} 3$ & KO189 & KO189 \\
\hline
\end{tabular}

FIG. 4. Influence of $\operatorname{omp} X$ expression on the production of type 1 fimbriae as assessed by quantitative agglutination of yeast cells in Tris-buffered saline (A) and by Western analysis (B). The results are representative of the results of at least three experiments.

the fimbriated ompX-deficient strain $\mathrm{KO} 3$ (Fig. 5A), as well as by overexpression of type 1 fimbriae (Fig. 5B). This phenotype was lost in a fim ompX double mutant, whose swarming behavior was comparable to that of the nonfimbriated parent strain MS7 (Fig. 5C). Thus, reduced motility is another phenotype of the $\operatorname{ompX}$ mutant, which is probably related to the change in expression of type 1 fimbriae.

Production of EPS is increased in ompX-deficient strains. On MacConkey medium and minimal medium, the $o m p X$ deletion strains developed a mucoid colony phenotype after 2 days of incubation at $30^{\circ} \mathrm{C}$ (Fig. 6A). Based on this observation and since biofilm formation is often associated with increased production of EPS, we tested whether the strains differed in production of the extracellular matrix, which may influence the dynamic interactions of the cells with the surface. EPS production by the different strains was estimated by hydrolysis of precipitated EPS with sulfuric acid. Independent of the presence of fimbriae, inactivation of $\mathrm{ompX}$ resulted in an approximately threefold increase in the production of EPS (Fig. 6B). The EPS production in the ompX overexpression strains did not differ from that in the parental strains (data not shown).

Inactivation of OmpX results in increased tolerance to SDS and antibiotic compounds. To test whether the phenotype of mutants that differed in the level of expression of ompX correlated with altered tolerance to stress and antibiotics, we determined the resistance to several stress conditions and different antibiotic compounds for cells starved for $24 \mathrm{~h}$ in $0.2 \mathrm{M}$ Tris-buffered saline ( $\mathrm{pH} 7.5)$. The pattern of resistance to SDS $(0.4 \%)$ and various antibiotics changed with the level of $o m p X$ expression (Table 3). The ompX-deficient strains KO3 and KO6 were more resistant to SDS than their parental strains. Furthermore, deletion of $\mathrm{omp} X$ resulted in higher tolerance to hydrophobic antibiotics, such as amikacin, cephalothin, gentamicin, nalidixic acid, novobiocin, and compound sulfonamides. In a nonfimbriated strain background similar resistance patterns were found. On the other hand, the levels of resistance to 10 or $20 \%$ ethanol or heat stress were not significantly different for the different strains (data not shown). These results suggest that deletion of ompX does not turn on a stress response but affects transport of hydrophobic compounds across the membrane.

\section{DISCUSSION}

When bacteria adhere to a surface, they encounter profound alterations in their environment. To adjust appropriately, a subset of genes is activated, and expression of other genes is repressed $(21,34)$. Previously, we identified OmpX as one of several outer membrane proteins present at a significantly lower level during adhesion of type 1 fimbriated $E$. coli than in planktonic cells (31). In the present study, we extended this finding to show that inactivation of $o m p X$ in $E$. coli promotes cell-surface interactions of type 1 fimbriated cells, as shown by use of the QCM-D technique, which simultaneously measures the increase in attached mass on the surface and changes in the viscoelastic properties of the cell-surface contact area. In addition, the expression of $\mathrm{ompX}$ influences the production of type 1 fimbriae, motility, and the production of EPS, as well as antibiotic resistance, thus controlling phenotypes typically altered in surface-associated bacteria.

Attempts to understand the development of bacterial biofilms and their characteristic attributes often concentrate on either identifying factors involved in the initial adhesion event or analyzing phenotypes developed by mature biofilms. The first nonspecific interactions of a cell with a surface are largely influenced by overall cell surface properties, such as charge and hydrophobicity. These parameters were only slightly affected by the absence of OmpX. Even the numbers of attached cells were similar for the different strains. This suggests that changes in ompX expression do not influence the initial affinity of cells for a surface.

However, the analytical power of the QCM-D technique allows detection of changes in the direct contact area between the adhering cells and the surface. This approach shows that the altered level of OmpX plays an important role in mediating changes in the cell-surface contact following attachment. Changes in frequency and dissipation shifts due to cell-surface interactions revealed that the ompX-deficient strain $\mathrm{KO} 3$ appears to exhibit increased cell-surface contact, which is accompanied by an increase in energy dissipation. Moreover, the adhesion responses of this mutant were clearly different on hydrophilic and hydrophobic surfaces. Although during the first $30 \mathrm{~min}$ of adhesion almost threefold-higher frequency shifts per attached cell were observed on hydrophobic surfaces 

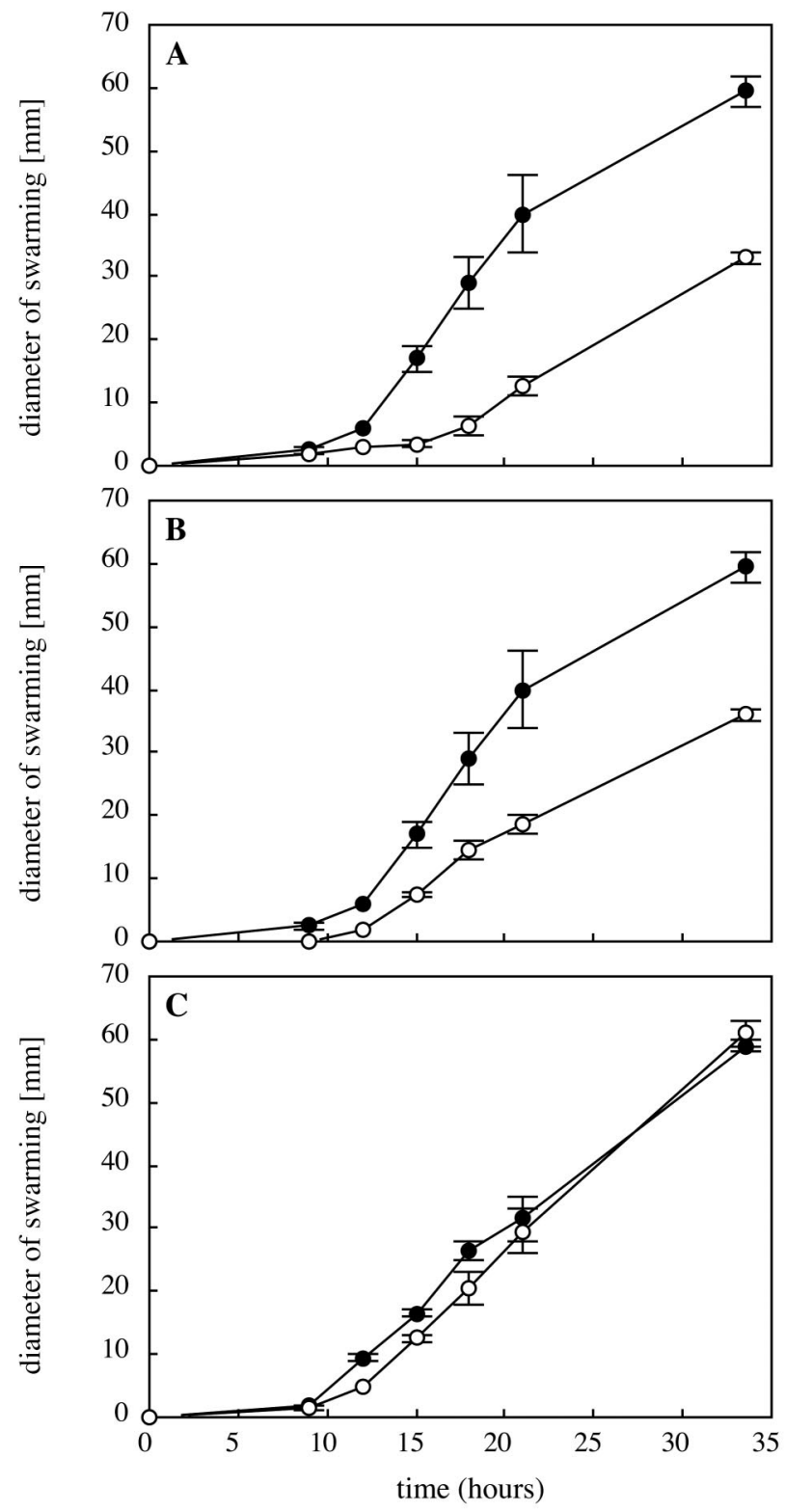

FIG. 5. Influence of ompX expression on motility of strains. (A) Symbols: - wild-type strain PC31; $\bigcirc$, ompX mutant $\mathrm{KO} 3$. (B) Symbols: $\bullet$, wild-type strain PC31; $\bigcirc$, strain MS7fim + overexpressing type 1 fimbriae. (C) Symbols: $\bullet$, nonfimbriated strain MS7; $\bigcirc$, nonfimbriated ompX mutant KO6. Motility tests on soft agar plates were repeated at least three times, and the data are means \pm standard deviations (error bars) from one representative experiment.

than on hydrophilic surfaces, prolonged incubation resulted in a continued increase in the contact area between attached cells and hydrophilic surfaces. This suggests that intimate contact between a cell and a surface is established more rapidly on hydrophobic surfaces, which may be explained at least in part by structural changes in the cell surface. As previously shown for hyperfimbriated cells (29), cell-surface interactions occur more slowly on hydrophilic surfaces. In the case of an ompX mutant this may be due to the effect of a more negative cell
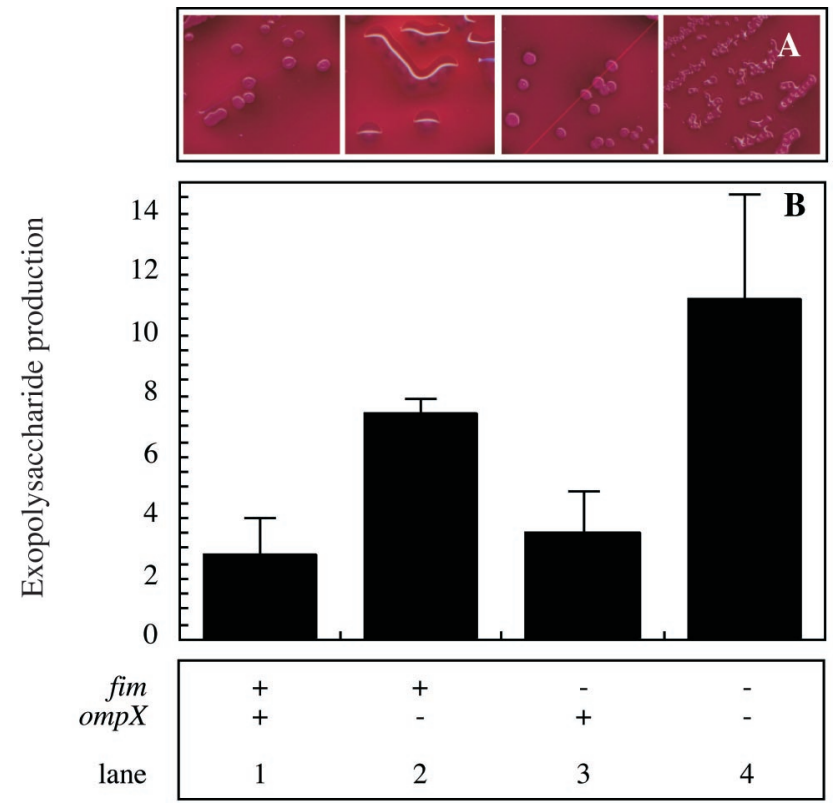

FIG. 6. Effect of ompX expression on production of EPS. (A) Colony phenotypes of fimbriated and nonfimbriated $E$. coli wild-type and ompX mutant strains after 2 days of incubation at $30^{\circ} \mathrm{C}$ on MacConkey agar. The elongated appearance of $\mathrm{KO} 3$ colonies is due to EPS surrounding several colonies close to each other. (B) Quantitative estimation of EPS production by the same strains. The amount of EPS is expressed as $10^{-8}$ microgram per cell, and the number of cells was determined by determining the number of CFU per milliliter. The data are the data for wild-type strain PC31 (lane 1), ompX mutant KO3 (lane 2), nonfimbriated strain MS7 (lane 3), and nonfimbriated ompX mutant KO6 (lane 4). The data are means \pm standard deviations (error bars) from three experiments.

surface charge on electrostatic interactions involved in adhesion to hydrophilic surfaces.

We also investigated the role of $\operatorname{omp} X$ expression in adhesion of a strain lacking the fim operon. Interestingly, an opposite effect on adhesion was observed, and there was strongly decreased cell-surface contact with the nonfimbriated ompXdeficient strain KO6, especially on hydrophobic surfaces. One possible explanation for this is that OmpX functions as an adhesin when fimbriae are not expressed. However, if this were true, we would expect a decrease in the number of attached cells of the nonfimbriated $\operatorname{omp} X$ deletion strain, which is not the case. We believe that the decreased interactions displayed by a nonfimbriated $\operatorname{omp} X$ mutant may reflect a defect in an adaptive response to surface contact that requires type 1 fimbriae. This idea is supported by the finding that production of type 1 fimbriae is upregulated in the $o m p X$ deletion strain.

It has been shown previously that hyperfimbriated cells cause low-level frequency and dissipation shifts compared to the shifts caused by nonfimbriated cells (29), whereas in this study the increased fimbriation of the $\mathrm{omp} X$ deletion strain was accompanied by increased frequency and dissipation shifts. This suggests that inactivation of OmpX causes additional changes in the cell surface that influence the cell-surface interactions. It has been suggested that flagella are involved in the initial interactions of bacteria with surfaces, either by mediating direct contact with the surface or by conferring motility 
TABLE 3. Influence of $o m p X$ expression on tolerance to SDS and antibiotic compounds

\begin{tabular}{|c|c|c|c|c|c|c|c|c|}
\hline \multirow[b]{2}{*}{ Strain } & \multirow[b]{2}{*}{ Relevant genotype } & \multirow{2}{*}{$\begin{array}{c}\% \text { Survival in } \\
\text { the presence } \\
\text { of SDS } \\
(0.4 \%)^{a}\end{array}$} & \multicolumn{6}{|c|}{ Radius of inhibition zone $(\mathrm{mm})$ in the presence of: } \\
\hline & & & Amikacin $(30 \mu \mathrm{g})$ & $\begin{array}{l}\text { Cephalosporin } \\
\quad(30 \mu \mathrm{g})\end{array}$ & $\begin{array}{l}\text { Gentamicin } \\
\quad(10 \mu \mathrm{g})\end{array}$ & Novobiocin $(30 \mu \mathrm{g})$ & $\begin{array}{l}\text { Nalidixic acid } \\
\quad(30 \mu \mathrm{g})\end{array}$ & $\begin{array}{l}\text { Compound sulfonamides } \\
\qquad(300 \mu \mathrm{g})\end{array}$ \\
\hline PC31 & Wild type & $43 \pm 19$ & $8.9 \pm 0.2$ & $4.4 \pm 0.2$ & $8.0 \pm 0.6$ & $3.8 \pm 0.2$ & $9.5 \pm 0.6$ & $6.4 \pm 0.7$ \\
\hline KO3 & $\Delta o m p X:: c a m$ & $70 \pm 14$ & $5.3 \pm 0.7$ & $1.1 \pm 0.2$ & $4.8 \pm 0.6$ & 0 & $3.3 \pm 0.5$ & 0 \\
\hline MS7 & fim::kan & $22 \pm 6$ & $8.3 \pm 0.7$ & $4.2 \pm 0.3$ & $8.0 \pm 1.0$ & $3.8 \pm 0.3$ & $9.2 \pm 0.6$ & $5.6 \pm 0.2$ \\
\hline KO6 & $\Delta o m p X:: c a m$ fim::kan & $62 \pm 5$ & $6.5 \pm 0.3$ & $1.1 \pm 0.2$ & $4.7 \pm 0.4$ & 0 & $3.4 \pm 0.6$ & $0.2 \pm 0.2$ \\
\hline
\end{tabular}

${ }^{a}$ The viability of cells was determined by determining the numbers of CFU per milliliter before and after 5 min of exposure to SDS.

to the cells and increasing their transport to the surface $(18,28$, 33). We found that the fimbriated $\mathrm{omp} X$ deletion strain was less motile than the wild type, which is likely to increase immobilization of cells on a surface and may explain the improved cell-surface interactions. However, the same phenotype is exhibited when fimbriae are overexpressed, whereas the motility of the nonfimbriated $o m p X$ strain does not differ from that of its parental strain. This suggests that reduced motility is not directly affected by the absence of OmpX but rather is indirectly affected by the upregulation of fimbriae. This could be due to physical interference between fimbriae and flagella, or it could be because synthesis of these surface appendages may be oppositely controlled, as has recently been demonstrated for $S$. enterica serovar Typhimurium (6).

Deletion of $\operatorname{ompX}$ also causes an approximately threefold increase in the production of EPS. Bacterial colonization of surfaces is often associated with the presence of EPS (10), and it has been established that the role of EPS is to bridge attached cells to a surface during prolonged colonization rather than to mediate the initial adhesion $(3,9)$. The combined effects of $o m p X$ on fimbria production, motility, and EPS production may account for the different binding properties of fimbriated and nonfimbriated $\mathrm{omp} X$ mutants.

Bacteria attached to a surface are evidently in a physiological state different from that of planktonic cells, and a common problem associated with biofilms is their increased tolerance to antimicrobial agents (20). However, attempts to prove that a specific multidrug efflux pump has a role in the resistance of biofilms have so far been unsuccessful $(11,21)$. Particularly in this context, it is interesting that inactivation of $o m p X$ results in increased tolerance to exposure to SDS and several hydrophobic antibiotics. The increased antibiotic resistance of ompX mutants is independent of the presence of fimbriae and may be explained at least in part by the observed increase in EPS production in these strains. In addition, it is possible that OmpX directly or indirectly affects a transport function. Since the crystal structure of the protein does not suggest a pathway between the periplasm and the external surface (43), OmpX is unlikely to function as a transporter itself. However, given the fact that several outer membrane proteins are expressed at a lower level during adhesion (31), it is possible that OmpX is coregulated or interacts with an outer membrane pore that mediates the import of hydrophobic molecules.

We propose the following model to explain surface-induced changes during adhesion of fimbriated E. coli cells. Due to phase variation of type 1 fimbria expression, a population of an $E$. coli wild-type strain contains both fimbriated and nonfimbriated cells with characteristic binding properties (29). Con- tact of fimbriated cells with a surface results in a decrease in the level of outer membrane proteins (31). The reduced level of at least one of these proteins, OmpX, may serve as an important signal for the cell to change expression of other cell surface structures in order to strengthen the cell-surface contact. As a consequence, the production of type 1 fimbriae and EPS production are upregulated, whereas motility is reduced. This not only may influence cell-surface interactions but also may confer the higher antibiotic resistance associated with biofilm bacteria.

Although it is not clear from this study how the observed changes are regulated, recent studies have shown that OmpX is under control of different regulatory systems. ompX is a member of the mar regulon (2), which has been shown to be repressed in biofilms (21). Second, expression of OmpX is decreased by inactivation of $\mathrm{H}-\mathrm{NS}$, a global regulator protein which has also been shown to negatively affect adhesion of $E$. coli (19). Moreover, OmpX has been found to be induced at either $\mathrm{pH}$ extreme (38). This indicates that a complex network of regulatory systems is important for the developmental change that occurs during the initial phase of biofilm formation.

Overexpression of $\operatorname{omp} X$ has been shown to activate $\sigma^{\mathrm{E}}$, but deletion of $\operatorname{omp} X$ does not affect $\sigma^{\mathrm{E}}$ activity (24). $\sigma^{\mathrm{E}}$ regulates gene expression in response to cell envelope stress and partially overlaps in this function with the CpxRA two-component system, which is also induced by surface contact and is required for adhesion (32). In agreement with the low level of OmpX during adhesion, $\sigma^{\mathrm{E}}$ is not induced upon surface contact (32). On the other hand, deletion of $\operatorname{omp} X$ does not cause an increase in the transcriptional activity of $c p x R$ either (data not shown). Further experiments are required to elucidate how changes in the levels of outer membrane proteins are connected to regulatory systems controlling early steps of biofilm development.

In summary, the results of this study demonstrate that the expression of OmpX is related to changes in the adhesive properties of $E$. coli. In addition to the previously described importance of cell surface structures such as fimbriae, flagella, and EPS in the formation of biofilms, it is interesting that a change in the abundance of a single outer membrane protein influences these parameters and may be an important early signal in a series of postattachment events. It should also be considered that during adhesion the levels of a range of outer membrane proteins change and that the effects on cell surface properties and adhesion may be even more pronounced. The pleiotropic effects of ompX expression on adhesive cell surface structures may explain why the reduced abundance of OmpX, 
as observed during adhesion to abiotic surfaces (31), contributes to increased cell-surface contact for strains with a fimbriated background. Based on these results, we suggest that changes in the composition of outer membrane proteins during fimbria-mediated adhesion to abiotic surfaces (31) may be part of an adaptational response of $E$. coli cells to the attached mode of growth.

\section{ACKNOWLEDGMENTS}

We thank Carol Gross and Per Klemm for supplying strains and Scott Hultgren for providing the FimA antiserum.

This work was financially supported by a grant from the Foundation for Strategic Research through the Marine Science and Technology (MASTEC) Program to M.H., by a grant from the Adlerbertska Science Foundation to K.O., and by the Swedish Research Council.

\section{REFERENCES}

1. Absolom, D. R., F. V. Lamberti, Z. Policova, W. Zingg, C. J. van Oss, and A. W. Neumann. 1983. Surface thermodynamics of bacterial adhesion. Appl. Environ. Microbiol. 46:90-97.

2. Alekshun, M. N., and S. B. Levy. 1997. Regulation of chromosomally mediated multiple antibiotic resistance: the mar regulon. Antimicrob. Agents Chemother. 41:2067-2075.

3. Allison, D. G., and I. W. Sutherland. 1987. The role of exopolysaccharides in adhesion of freshwater bacteria. J. Gen. Microbiol. 133:1319-1327.

4. Barondess, J. J., and J. Beckwith. 1990. A bacterial virulence determinant encoded by lysogenic coliphage lambda. Nature 346:871-872.

5. Casadaban, M. J., and S. N. Cohen. 1980. Analysis of gene control signals by DNA fusion and cloning in Escherichia coli. J. Mol. Biol. 138:179-207.

6. Clegg, S., and K. T. Hughes. 2002. FimZ is a molecular link between sticking and swimming in Salmonella enterica serovar Typhimurium. J. Bacteriol 184:1209-1213.

7. Climent, N., S. Ferrer, X. Rubires, S. Merino, J. M. Tomás, and M. Regué. 1997. Molecular characterization of a $17-\mathrm{kDa}$ outer-membrane protein from Klebsiella pneumoniae. Res. Microbiol. 148:133-143.

8. Dall, L., and B. Herndon. 1989. Quantitative assay of glycocalyx produced by viridans group streptococci that cause endocarditis. J. Clin. Microbiol. 27: 2039-2041.

9. Danese, P. N., L. A. Pratt, and R. Kolter. 2000. Exopolysaccharide production is required for development of Escherichia coli K-12 biofilm architecture. J. Bacteriol. 182:3593-3596.

10. Davies, D. G., A. M. Chakrabarty, and G. G. Geesey. 1993. Exopolysaccharide production in biofilms: substratum activation of alginate gene expression by Pseudomonas aeruginosa. Appl. Environ. Microbiol. 59:1181-1186.

11. De Kievit, T. R., M. D. Parkins, R. J. Gillis, R. Srikumar, H. Ceri, K. Poole, B. H. Iglewski, and D. G. Storey. 2001. Multidrug efflux pumps: expression patterns and contribution to antibiotic resistance in Pseudomonas aeruginosa biofilms. Antimicrob. Agents Chemother. 45:1761-1770.

12. de Kort, G., A. Bolton, G. Martin, J. Stephen, and J. A. M. van de Klundert. 1994. Invasion of rabbit ileal tissue by Enterobacter cloacae varies with the concentration of OmpX in the outer membrane. Infect. Immun. 62:47224726 .

13. Derjaguin, B. V., and L. Landau. 1941. Theory of the stability of strongly charged hydrophobic sols and of the adhesion of strongly charged particles in solutions of electrolytes. Acta Physicochim. URSS 14:633-662.

14. Guzman, L., D. Belin, M. J. Carson, and J. Beckwith. 1995. Tight regulation, modulation, and high-level expression by vectors containing the arabinose $\mathrm{P}_{\mathrm{BAD}}$ promoter. J. Bacteriol. 177:4121-4130.

15. Heffernan, E. J., J. Harwood, J. Fierer, and D. Guiney. 1992. The Salmonella typhimurium virulence plasmid complement resistance gene rck is homologous to a family of virulence-related outer membrane protein genes, including pagC and ail. J. Bacteriol. 174:84-91.

16. Höök, F., M. Rodahl, and B. Kasemo. 1998. Energy dissipation kinetics for protein and antibody-antigen adsorption under shear oscillation on a quartz crystal microbalance. Langmuir 14:729-734.

17. Klemm, P., B. J. Jørgensen, I. van Die, H. de Ree, and H. Bergmans. 1985 The fim genes responsible for synthesis of type 1 fimbriae in Escherichia coli, cloning and genetic organization. Mol. Gen. Genet. 199:410-414.

18. Korber, D. R., J. R. Lawrence, and D. E. Caldwell. 1994. Effect of motility on surface colonization and reproductive success of Pseudomonas fluorescens in dual-dilution continuous culture and batch culture systems. Appl. Environ. Microbiol. 60:1421-1429.
19. Landini, P., and A. J. B. Zehnder. 2002. The global regulatory hns gene negatively affects adhesion to solid surfaces by anaerobically grown Escherichia coli by modulating expression of flagellar genes and lipopolysaccharide production. J. Bacteriol. 184:1522-1529.

20. Mah, T.-F. C., and G. A. O'Toole. 2001. Mechanisms of biofilm resistance to antimicrobial agents. Trends Microbiol. 9:34-39.

21. Maira-Litran, T., D. G. Allison, and P. Gilbert. 2000. Expression of the multiple antibiotic resistance operon (mar) during growth of Escherichia coli as a biofilm. J. Appl. Microbiol. 88:243-247.

22. Maniatis, T., E. F. Fritsch, and J. Sambrook. 1982. Molecular cloning: a laboratory manual. Cold Spring Harbor Laboratory, Cold Spring Harbor, N.Y.

23. Mecsas, J., P. E. Rouviere, J. W. Erickson, T. J. Donohue, and C. A. Gross. 1993. The activity of $\sigma^{\mathrm{E}}$, an Escherichia coli heat-inducible $\sigma$-factor, is modulated by expression of outer membrane proteins. Genes Dev. 7:2618-2628.

24. Mecsas, J., R. Welch, J. W. Erickson, and C. A. Gross. 1995. Identification and characterization of an outer membrane protein, OmpX, in Escherichia coli that is homologous to a family of outer membrane proteins including Ail of Yersinia enterocolitica. J. Bacteriol. 177:799-804

25. Miller, J. H. 1973. Experiments in molecular genetics. Cold Spring Harbor Laboratory, Cold Spring Harbor, N.Y.

26. Miller, V. L., K. B. Beer, G. Heusipp, B. M. Young, and M. R. Wachtel. 2001. Identification of regions of Ail required for the invasion and serum resistance phenotypes. Mol. Microbiol. 41:1053-1062.

27. Mulvey, M. A., Y. S. Lope-Boado, C. L. Wilson, R. Roth, W. C. Parks, J. Heuser, and S. J. Hultgren. 1998. Induction and evasion of host defenses by type 1-piliated uropathogenic Escherichia coli. Science 282:1494-1497.

28. O'Toole, G. A., and R. Kolter. 1998. Flagellar and twitching motility are necessary for Pseudomonas aeruginosa biofilm development. Mol. Microbiol. 30:295-304.

29. Otto, K., H. Elwing, and M. Hermansson. 1999. Effect of ionic strength on the initial interactions of Escherichia coli with surfaces studied on-line by a novel quartz crystal microbalance. J. Bacteriol. 181:5210-5218.

30. Otto, K., H. Elwing, and M. Hermansson. 1999. The role of type-1 fimbriae in adhesion of Escherichia coli to hydrophilic and hydrophobic surfaces. Colloids Surf. B Biointerf. 15:99-111.

31. Otto, K., J. Norbeck, T. Larsson, K.-A. Karlsson, and M. Hermansson. 2001 Adhesion of Escherichia coli to abiotic surfaces leads to altered composition of outer membrane proteins. J. Bacteriol. 183:2445-2453.

32. Otto, K., and T. J. Silhavy. 2002. Surface sensing and adhesion of Escherichia coli under control of the Cpx signalling pathway. Proc. Natl. Acad. Sci. 99:2287-2292.

33. Pratt, L. A., and R. Kolter. 1998. Genetic analysis of Escherichia coli biofilm formation: roles of flagella, motility, chemotaxis and type I pili. Mol. Microbiol. 30:285-293.

34. Prigent-Combaret, C., O. Vidal, C. Dorel, and P. Lejeune. 1999. Abiotic surface sensing and biofilm-dependent regulation of gene expression in Escherichia coli. J. Bacteriol. 181:5993-6002.

35. Prime, K. L., and G. M. Whitesides. 1991. Self-assembled organic monolayers: model systems for studying adsorption of proteins at surfaces. Science 252:1164-1167.

36. Rodahl, M., F. Höök, and B. Kasemo. 1996. QCM operations in liquids: an explanation of measured variations in frequency and $\mathrm{Q}$ factor with liquid conductivity. Anal. Chem. 68:2219-2227.

37. Schembri, M. A., L. Pallesen, H. Connell, D. L. Hasty, and P. Klemm. 1996. Linker insertion analysis of the FimH adhesin of type 1 fimbriae in an Escherichia coli fimH-null background. FEMS Microbiol. Lett. 137:257-263.

38. Stancik, L. M., D. M. Stancik, B. Schmidt, D. M. Barnhart, Y. N. Yoncheva, and J. L. Slonczewski. 2002. pH-dependent expression of periplasmic proteins and amino acid catabolism in Escherichia coli. J. Bacteriol. 184:42464258 .

39. Stentebjerg-Olesen, B., L. Pallesen, L. Bogø Jensen, G. Christiansen, and P. Klemm. 1997. Authentic display of a cholera toxin epitope by chimeric type 1 fimbriae: effects of insert position and host background. Microbiology 143:2027-2038.

40. Stoorvogel, J., M. J. A. W. M. van Bussel, and J. A. M. van de Klundert. 1991. Biological characterization of an Enterobacter cloacae outer membrane protein (OmpX). J. Bacteriol. 173:161-167.

41. Van Oss, C. J. 1994. Interfacial forces in aqueous media. Marcel Dekker, New York, N.Y

42. Verwey, E. J. W., and J. T. G. Overbeek. 1948. Theory of the stability of lyophobic colloids. Elsevier, Amsterdam, The Netherlands.

43. Vogt, J., and G. E. Schulz. 1999. The structure of the outer membrane protein OmpX from Escherichia coli reveals possible mechanisms of virulence. Structure Fold Des. 7:1301-1309.

44. Zhang, J. P., and S. Normark. 1996. Induction of gene expression in Escherichia coli after pilus-mediated adherence. Science 273:1234-1236. 